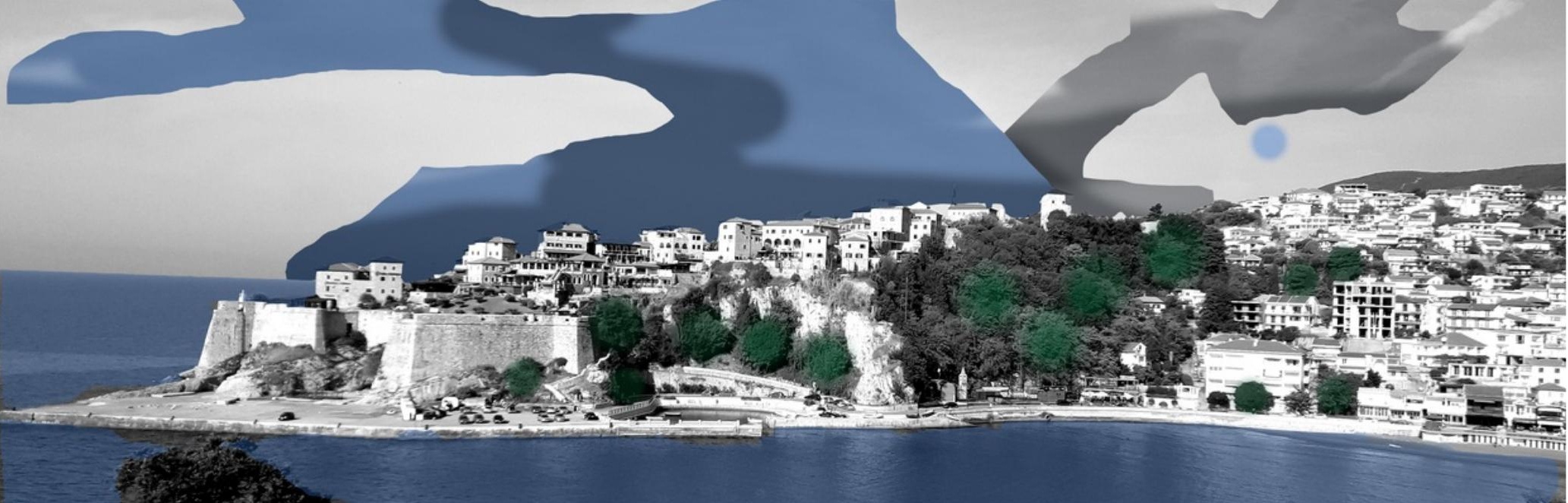

\title{
Architectural Design Process: Consulting with Nature
}

Authors: $\quad$ Bujar Q. Bajçinovci, Bard Bajçinovci, Uliks Bajçinovci

Submitted: 9. March 2020

Published: 11. March 2020

Volume:

Issue:

Affiliation:

Languages:

Keywords:

Categories:

DOI:

7

2

Abstract:

University of Prishtina, Faculty of Civil Engineering and Architecture, Kosovo.

English

Architectural design process, Environment, Nature, Biodiversity, Urban Planning.

Visual Arts, Architecture and Design, Life Sciences

10.17160/josha.7.2.643

In the continuum of evolution and adaptation of living organisms, ranging from microorganisms to human beings, there are certain cycles of time that carry with its cardinal changes that human beings must face and find the best possible harmony of eligibility. The new millennium brings with it a new lifestyle as a result of a number of determining factors, driven by technology development and the phenomenon of globalization. Therefore, we have come into a situation where a number of questions need to be raised about the necessity of redefining many daily life habits. The study presented in this paper investigated the architectural design process to consult with nature, where to many urban structures are being ruined in the name of sustainable architecture. We are constantly experiencing original situations known by intuition, but we have forgotten them, remembering the same thing can be ten times faster. Similar cases also occur on the global level, reflected in the world market, when in the context of globalization one can at a working table make a decision on a part of the alobal market. and thus directlv affect the world price. which affects

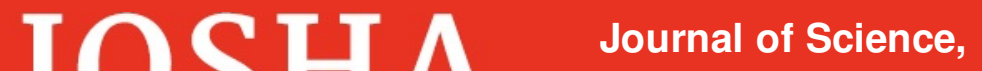 Humanities and Arts}




\title{
Architectural Design Process: Consulting with Nature
}

\author{
Bujar Bajçinovci ${ }^{1^{*}}$, Bard Bajçinovci ${ }^{2}$, Uliks Bajçinovci ${ }^{2}$ \\ ${ }^{1}$ University of Prishtina, Faculty of Architecture, Kosovo. \\ ${ }^{2}$ UBT-Higher Education Institution. Faculty of Architecture and Spatial Planning, Kosovo.
}

Email:bujar.bajcinovci@uni-pr.edu,bb34218@ubt-uni.net,.ub35398@ubt-uni.net

\begin{abstract}
:
In the continuum of evolution and adaptation of living organisms, ranging from microorganisms to human beings, there are certain cycles of time that carry with its cardinal changes that human beings must face and find the best possible harmony of eligibility. The new millennium brings with it a new lifestyle as a result of a number of determining factors, driven by technology development and the phenomenon of globalization. Therefore, we have come into a situation where a number of questions need to be raised about the necessity of redefining many daily life habits. The study presented in this paper investigated the architectural design process to consult with nature, where to many urban structures are being ruined in the name of sustainable architecture. We are constantly experiencing original situations known by intuition, but we have forgotten them, remembering the same thing can be ten times faster. Similar cases also occur on the global level, reflected in the world market, when in the context of globalization one can at a working table make a decision on a part of the global market, and thus directly affect the world price, which affects us too! The current and possible degraded state of environment in the name of urbanization are not acceptable, even more, when the sources of natural capacities are being ruined.
\end{abstract}

Key words: Architectural design process, Environment, Nature, Biodiversity, Urban Planning.

\section{INTRODUCTION}

In the continuum of evolution and adaptation of living organisms, ranging from microorganisms to human beings, there are certain cycles of time that carry with its cardinal changes that human beings must face and find the best possible harmony of eligibility. The daily challenges must stimulate new scientific research and really need to be directed at utilizing all the resources, above all, the mental ones in order to ensure a better quality of life. Architecture, in terms of transdisciplinary activities as well as its participation in solving design problems, can solve future challenges with appropriate and contemporary strategies. The new millennium brings with it a new lifestyle as a result of a number of determining factors, driven by technology development and the phenomenon of globalization [1]. Therefore, we have come into a situation where a number of questions need to be raised about the necessity of redefining many daily life habits. Despite the practical validation and advantages of the integrated design process in architecture, there are certain difficulties and limitations in not implementing natural and 
evolving design strategies conditional on new lifestyles, technological development, globalization and redefining the phenomenon of design values up to now. Architectural design faces major challenges, as a result of evident climate change, as well as completely new lifestyles, furthermore, globalization is described as a process in which regional economies, societies and cultures integrate through a global network of political ideas, communication, transport and integral value of the global market. The phenomenon of globalization is an unstoppable historical process that reflects with relevant technological innovations, science, new economic and ecological strategies. While ancient cultures, not using the word "ecology", have built with ecology in mind, otherwise ignorance would bring destruction, epidemics, hunger, social and class disintegration [1]. The architectural approach to holistic phenomena emphasizes the need to create harmony between the need for function and the rational design ideas expressed for particular situations and environments. The current practice of linear design is of a one-way or sequential nature of design process. We are witnessing the urgent need to address social and economic problems while at the same time experiencing environmental-local degradation. Scientific studies are relatively neglected in the residential construction sector, which should be carried out in terms of programming, planning and architectural design with a must approach to consult with nature. This is partly due to limited knowledge and limited information, inadequate urban policies, and partly due to the high initial pre design studies, in particular the efficiency of the construction sector [1]. "Cities are complex ecosystems with specific phenomenon's directly reflected in our health, natural resources, economic, social and aesthetic fields. They are open integrated systems and huge organisms with specific and complex metabolism that transform vast amount of energy, generate huge amount of waste and emanate a number of specific environmental phenomenon's and activities" [2].

\section{MATERIALS and METHODS}

The study presented in this paper investigated the architectural design process to consult with nature, where to many urban structures are being ruined in the name of sustainable architecture. Focusing on the urban morphology, legislation, sources for the renewable energy, and urban planning issues. The research methods consist of empirical observation through field, and literature review. In order to receive a clearer data, the research is made within spatial regulation, municipality actions, $\mathrm{m}$ focusing on the bioclimatic environment regarding to the morphology of the affected regions. The data collected include maps, composition of urban 
structure, attributes of the space, virtual dimensions of urban regions. The additional data for this paper is based on the right understanding of resource conservation for future generations, which consists in the fact that we are interdependent with the demand for natural resources and the empowerment of possible alternatives in preserving the ecosystem for the future. We have genuine examples from historiography of past civilizations and their disappearance as a phenomenon of depletion of the essential resources needed for living. Therefore, the approach and thinking that this phenomenon will happen to another generation rather than the current one, creates a false reality, as the entire ecosystem is in direct interaction and dependence of past, present and the future. It is generally known that facilities are users of at least half of the total energy produced in the world, such as: heating, lighting, air conditioning, refrigeration, and overall construction industry [1]. The greater proportion of this expenditure is directly related to architectural design process; hence, my essential maxim of sustainability will address two crucial issues: essentially there are lack of motivation being the harmonious with nature in metaphysics dimensions, and design strategies who in reality consult the nature to occupy the space. Architecture has always been involved in utilizing natural resources for human needs. Historically it has a long tradition of creating objects that communicate with the environment. Architectural design is facing major challenges as a result of globalization. The trend of globalization is an unstoppable historical process that will reflect on new technologies, science and evolutionary urban strategies. In the last decade, has globalization become a promoter of development, engaging in architecture with a dose of "loss of identity" and the specifics of a given local environment? Hence, there is a general consensus that regional and local identity will play an important role in the continuity of the diversity of culture and ethnological attributes, in which local and community identity is maintained [1]. The feeling that we belong to something, as part of the nature and whole universe, these are the elements and features of the new implementation of global sustainability, as well as in the architectural design process. The new millennium will bring fundamental life situations, which call into question the necessity of redefining our lifestyles.

\section{DISCUSSION}

It is understandable that not all architects can understand the problems of different special fields, but the professional design process begins with the first creative ideas in favor of solving a problem, followed by the development phase of the design scheme, then evaluate whether these ideas are in favor of the design solutions. Current design practice is currently defined as 
activities: the various designers in the project will meet periodically to ensure that their individual decisions are not in conflict, but most of the time staff will ensure that problems do not cross over with others [1]. On the other hand, the creative process acts as a collective system and evolves in all aspects of design. The design process is then organic, evolving, with the full participation of every expert. Respectively, there will be a number of ideas that will constantly be brought up as a possible solution. This type of iteration, iteration usually requires embodiment of each area of expertise and finally must consult the nature. Depending on the size and complexity of the project, it may also include the investor, prospective tenants, construction managers, and a wide range of individual advisors. All this is sublimated with a project, the best possible solution, especially if ideas are created when participants with cross boundaries of conventional and traditional thinking.

We are constantly experiencing original situations known by intuition, but we have forgotten them, remembering the same thing can be ten times faster. Similar cases also occur on the global level, reflected in the world market, when in the context of globalization one can at a working table make a decision on a part of the global market, and thus directly affect the world price, which affects us too! Similar situations occur, and will inevitably be reflected in the construction industry as well, which is really a relevant factor in generating gross financial revenue at the state coffers.

Architectural design has always been a pioneer of social change based on what is called modern and having the role of Avant Garde futuristic premises. In terms of comfort and quality of life the design process will strive to find the best possible solutions to the specific architectural problem, when new real-life functions are required. As never before, today we have experiencing multifunctional structures that are subject to the new demands of the time, coupled with advanced nano technologies. So, it really makes as evidently clear that a whole and homogeneous system are interdependent by subsystems which continuously are interacting together, especially when it comes to the synergy [1]. Therefore, "good" design, there are perfect scenarios and no perfect projects, however, there are conceptual guidelines that scientifically guide you towards the optimal solution of the proper design process. Strategic conceptual guidelines as guides for defining architectural problems and priorities should include many questions! 


\section{CONCLUSION}

The current and possible degraded state of environment in the name of urbanization are not acceptable, even more, when the sources of natural capacities are being ruined.

"In 1509, Italian mathematician Luca Pacioli, ... published Divina Proportione, a treatise on a number that is now widely known as the "Golden Ratio." This ratio, symbolized by ø, appears with amazing frequency in mathematics and nature...Logarithmic spirals are everywhereseashells, animal horns, the cochlea of the ear - anywhere nature needs to fill space economically and regularly. A spiral is strong and uses a minimum of materials. While expanding, it alters its size but never its shape." [Clifford A. Pickover, 2018], [3].

\section{REFERENCES}

[1] Bajçinovci, B. (2016). Sustainable Architectural Design - Principles - In the Albanian Language. Journal of Science, Humanities and Arts. Volume 4, Is. 3. DOI: 10.17160/josha.4.3.306

[2] Bajçinovci, B., Jerliu, F. (2016). Challenges of Architectural Design in relation to Environment and Air Pollution. A Case study: Prishtina's first public parking garage. Journal of Science, Humanities and Arts. Volume 3, Is. 7. DOI: 10.17160/josha.3.7.254

[3] Clifford A. Pickover. (2018). The Science Book: From Darwin to Dark Energy, 250 Milestones in the History of Science. Sterling Publishing Co. Inc. New York. 